\title{
The epidemiology of operations performed by the National Sea Rescue Institute of South Africa over a 5-year period
}

\author{
Elaine Erasmus ${ }^{1}$, Cleeve Robertson ${ }^{2}$, Daniel Jacobus van Hoving ${ }^{1}$
}

${ }^{1}$ Stellenbosch University Faculty of Medicine and Health Sciences, Cape Town, South Africa

${ }^{2}$ National Sea Rescue Institute of South Africa, Cape Town, South Africa

\begin{abstract}
Background: Injuries remain a major contributor of morbidity and mortality worldwide, with drowning accounting for $7 \%$ of all injury-related deaths with rates of between 4 and 8 per 100,000. The African region has death rates comparable to most low-income countries. Non-fatal drowning in Africa remains unquantified but it is estimated to be ten times higher than the fatal drowning rate. Timely search and rescue, initial resuscitation and rapid transportation to definitive care play a crucial role in preventing injury-related morbidity and mortality. The National Sea Rescue Institute (NSRI) of South Africa is a non-profit organisation responsible for $\sim 97 \%$ of maritime search and rescue operations in South Africa (including inland navigable waters). The aim of the study was to describe the epidemiology of operations performed by the NSRI of South Africa over a 5-year period.

Materials and methods: The NSRI operational database was analysed from 1 January 2010 to 31 December 2014. Summary statistics are presented.

Results: The NSRI launched 3281 operations over the study period. Marked seasonal variation were noticeable with peak periods in December and January, corresponding to the South African summer holiday season. Water-based operations (67.6\%) were the most frequent operation performed. The NSRI assisted 3399 individuals of which $77 \%$ were male. The mean age of rescued persons was 42 years. Eight hundred and thirty-six (25\%) individuals had non-fatal injuries or illnesses requiring medical assistance. Medical emergencies (35\%), traumatic injuries (32.8\%), and non-fatal drownings (23\%) were the most common types of injury and illness. The majority of the 184 (18\%) deaths recorded were due to drowning (75\%). Conclusions: Injury and illness, specifically drowning utilise a large proportion of search and rescue services. The results suggest further preventative measures and public health strategies be implemented to minimise traumatic and medical incident severity and subsequent casualties at sea.
\end{abstract}

(Int Marit Health 2018; 69, 1: 1-7

Key words: drowning, sea rescue, emergency medical services, South Africa, accident and emergency medicine, prehospital emergency care

\section{INTRODUCTION}

Non-natural deaths globally contribute significantly towards overall mortality. Injuries remain a major contributor of morbidity and mortality, accounting for more than $9 \%$ of total deaths worldwide [1]. South Africa is no exception as $11.1 \%$ of all deaths are deemed non-natural, which includes fatal motor vehicle accidents, assault, self-harm, and fatal drowning [2].
Drowning has been defined by the World Health Organisation (WHO) as "the process of experiencing respiratory impairment from submersion or immersion in liquid" [1]. More than 370,000 people die every year from drowning and over half of global drowning deaths are in persons younger than 25 years [1]. Males are twice as likely as females to drown, while drowning rates in low- and mid- 
dle-income countries are more than three times higher than in high-income countries [1]. This undoubtedly warrants drowning to be labelled as a globally neglected public health issue [1]. In South Africa fatal drowning occurred in 1411 people during 2015 , totalling $4.4 \%$ of other external causes of accidental injury [2]. However, true numbers of drowning are lacking and this number might be substantially higher [3]. The National Sea Rescue Institute (NSRI) of South Africa estimates that more than 2000 people die every year from drowning, 600 of which are children [personal communication: Dr. C. Robertson, August 2017]. These estimates are extrapolated from mortuary data in the Western Cape Province, but many drowning victims simply disappear in rivers, dams and the sea and it is likely that drowning is significantly under-reported.

Drowning is a highly preventable public health challenge and strategic interventions need to be undertaken to reduce the burden. Fundamental preventative strategies, especially in the young, include effective safety measures and barriers to control access to water (solid pool covers, pool fencing), improving water confidence and swimming skills, knowledge of rip currents, swimming on lifeguarded beaches, access to beach rescue equipment, warning signage, wearing of lifejackets by water users, bridges across rivers in rural areas, wetsuits or safe buoyancy aids for children, training bystanders and strengthening public awareness of drowning [1, 4]. Timely search and rescue of potential drowning victims (at sea or inland waters), initial appropriate resuscitation and rapid transportation to a medical facility also play a crucial role in preventing death.

Search and rescue (SAR) is defined as an operation initiated by emergency services to find individuals believed to be in distress, ill or injured; and possible lost in remotes areas or areas that are difficult to access [5]. SAR response is generally required in undeveloped, or extreme environments where misadventures tend to occur and modern emergency services or equipment are unable to reach. In order to locate the victim or vessel in distress, SAR personnel are exposed to the same inherent risks associated with wilderness, mountain and maritime activities [5]. The goal of SAR operations is to maximise the likelihood of success as swiftly as possible using available resources. The decision to terminate SAR efforts, if a victim is not found timeously, or to change to a search and recovery operation should be made based on the probability of survival [6]. Abandoning search and rescue efforts as the likelihood of survival diminishes, may reduce the risk to rescuers and conserve resources [6].

Maritime search and rescue is a subcomponent of search and rescue and has been defined by the Canadian Civil Air Search and Rescue Association (CASARA) as the search for, and provision of aid to persons, ships, or other crafts, which are, or feared to be, in distress or imminent danger. The rescue component denotes the part of the operation to retrieve persons in distress, provide for their initial medical or other needs, and deliver them to a place of safety [7]. The NSRI is a non-profit organisation responsible for the majority of search and rescue response along the South African coast and on inland navigable waters [8]. The NSRI consists of 31 coastal rescue stations, 5 inland dam bases, a fleet of 96 rescue crafts and \pm 1000 volunteers [8]. They assist with medical evacuations of crew from ships passing along the South African coastline, as well as commercial and subsistence fishermen. Rescue services also extend to recreational skiers, kite-surfers, windsurfers, surfers, sailors, and bathers requiring assistance at sea [8].

Systemised data from past search and rescue operations are crucial to current responses throughout the world [9-11]. For example, data can be used to identify high probability areas in certain regions. These areas can be explored beforehand to map relevant geographical features, to determine the swiftest access and egress routes, and to anticipate possible hazards that could be detrimental during a search and rescue operation. This will all help to ensure recovery of persons and vessels and limit patient mortality.

At present, there are no published studies describing the epidemiology of maritime search and rescue operations in South Africa. The paucity of data hampers the planning and execution of future search and rescue operations and are hindering the provision of lifesaving medical care in maritime environments. This study aimed to describe all search and rescue operations by the NSRI of South Africa over a 5-year period.

\section{MATERIALS AND METHODS}

\section{STUDY DESIGN}

A retrospective analysis of operations conducted by the South African NSRI over a 5-year period. The study was approved by the Health Research Ethics Committee at Stellenbosch University (Ref: S15/02/036).

\section{STUDY SETTING AND PARTICIPANTS}

Standardised operation capture forms (Appendix 1 see journal website) are completed after each mission by the NSRI shore controllers or the coxswains in charge which are then crosschecked by the rescue base Station Commander. Operation reports include demographic details and predefined data fields that record information about the incident as well as a narrative description of most cases. Validated crosschecked data is captured and individually stored on the NSRI Management Information System (MIS).

Operation reports of operations conducted from 1 January 2010 to 31 December 2014 were eligible for inclusion. Operation reports with incomplete data points relating to operation date or time, operation category and type, mission 


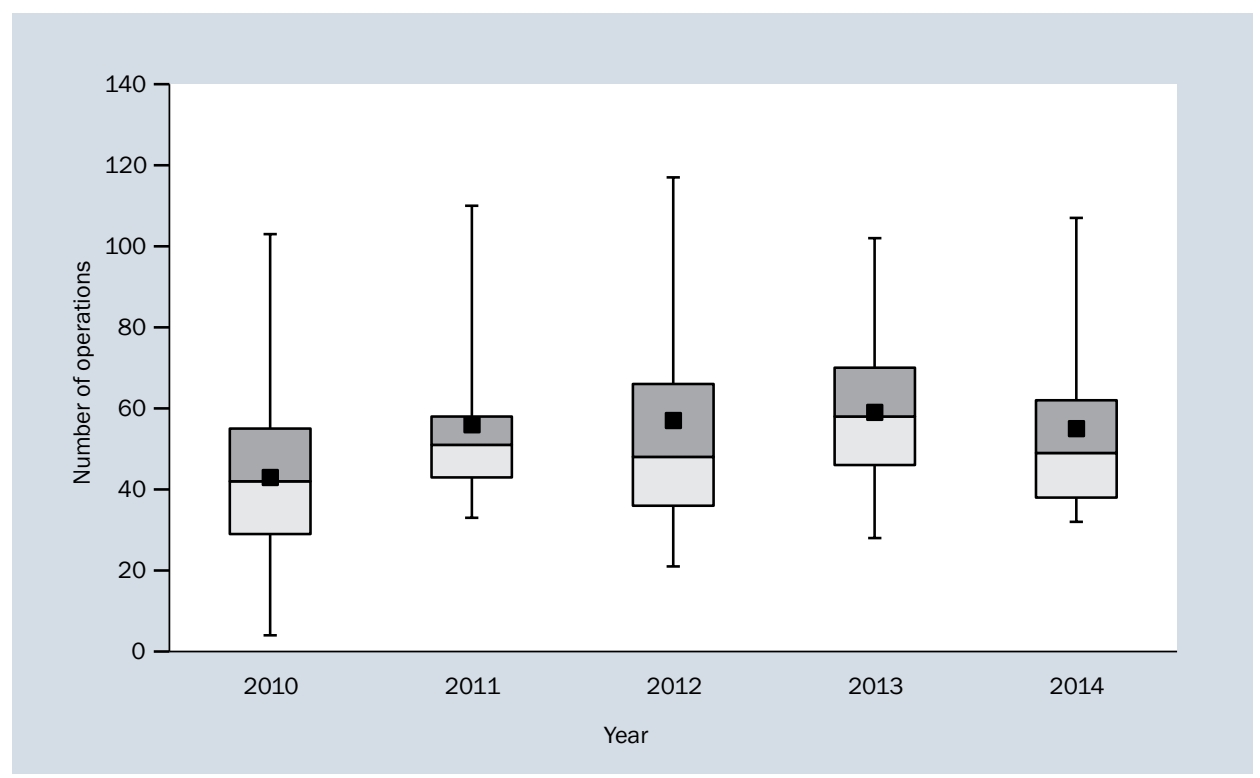

Figure 1. Annual operations performed by the National Sea Rescue Institute (black square represents the mean per month; endpoints of whiskers represent upper and lower extremes)

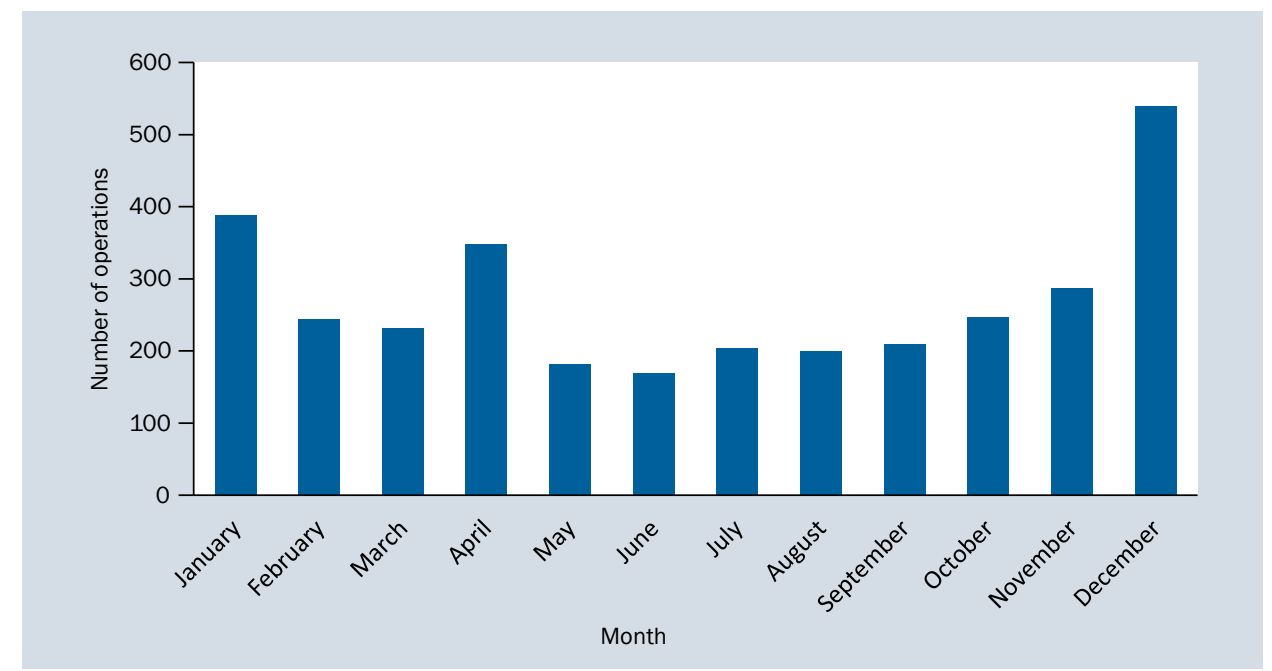

Figure 2. Total operations performed per month by the National Sea Rescue Institute of South Africa from January 2010 till December 2014

statistics and description were excluded from analysis. All double entries were also excluded.

\section{DATA COLLECTION AND MANAGEMENT}

Data from individual operation reports were manually incorporated into a Microsoft Exce ${ }^{\circledR}$ spreadsheet. Collected variables related to general mission information (operation number, region, and category), operation details (date, time, location), weather conditions (wind, swell, visibility) and demographics describing the rescued craft and person(s). Operations were categorized into four groups:

- air-based search and rescue;

- land-based search and rescue;
- water-based search and rescue;

- support services.

Further subcategorisation was done per incident type.

\section{STATISTICAL ANALYSIS}

Statistical analysis was done using Microsoft Excel ${ }^{\circledR}$, and summary statistics were used to describe all variables.

\section{RESULTS}

The NSRI performed 3281 operations over the 5-year period. Thirty-five (1.1\%) operations were excluded due to incomplete data points with 3246 operations subsequently included in the analysis (mean per year $=649.2$ ). Annual 


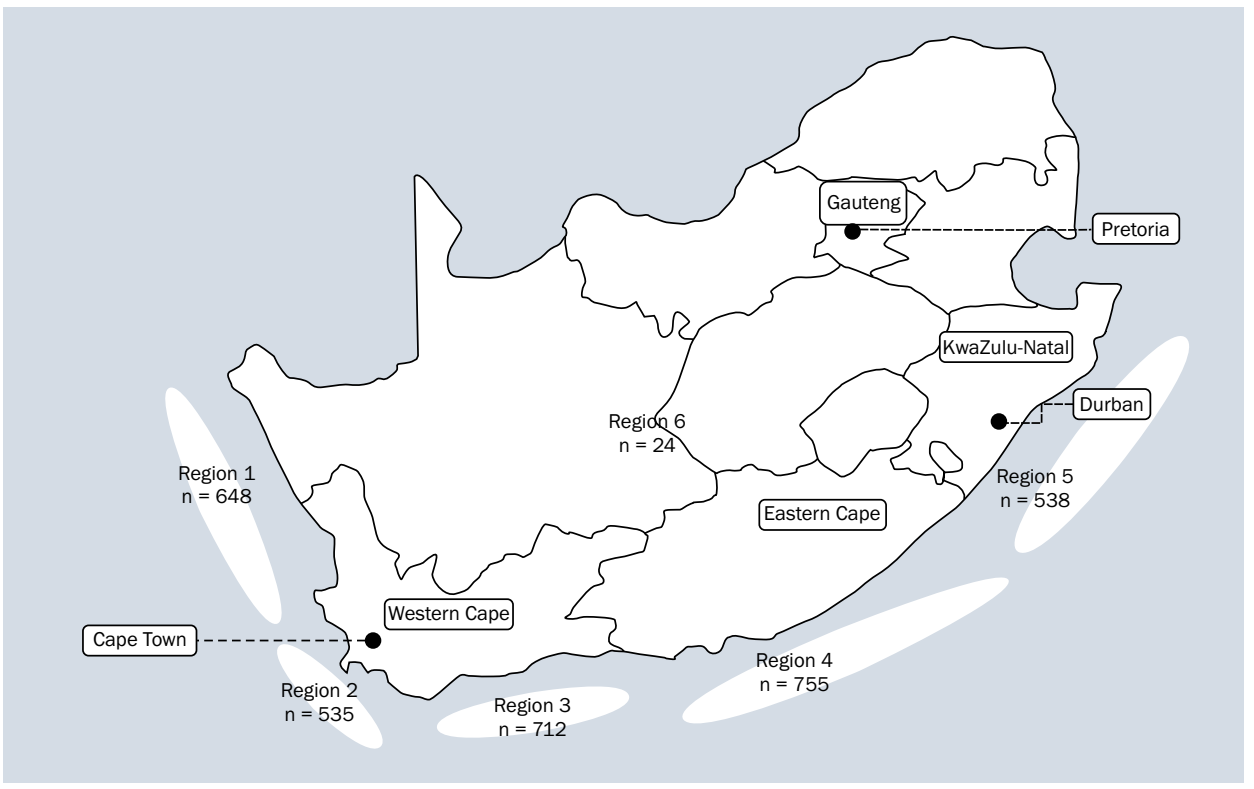

Figure 3. National Sea Rescue Institute operations per region for the 5-year period (Region 1: Lamberts Bay to Kommetjie; Region 2: Simons Town to Agulhas; Region 3: Witsand to Plettenberg Bay; Region 4: Oyster Bay to East London; Region 5: Richards Bay to Port St. Johns; Region 6: Inland)

Table 1. Weather conditions associated with operations performed by the National Sea Rescue Institute of South Africa

\begin{tabular}{llllll}
\hline Wind direction & $\mathbf{N}(\%)$ & Wind force & N (\%) & Swells & N (\%) \\
\hline South East & $1031(31.8 \%)$ & Force 0 - Calm $(<1 \mathrm{~km} / \mathrm{h})$ & $382(11.8 \%)$ & $<1 \mathrm{~m}$ & $917(28.2 \%)$ \\
South West & $766(23.6 \%)$ & Force 1 - Light air $(1-5 \mathrm{~km} / \mathrm{h})$ & $714(22 \%)$ & $1-2 \mathrm{~m}$ & $1296(40 \%)$ \\
North East & $392(12.1 \%)$ & Force 2 - Light breeze $(6-11 \mathrm{~km} / \mathrm{h})$ & $644(19.8 \%)$ & $2-3 \mathrm{~m}$ & $626(19.2 \%)$ \\
North West & $302(9.3 \%)$ & Force 3 - Gentle breeze $(12-19 \mathrm{~km} / \mathrm{h})$ & $468(14.4 \%)$ & $3-4 \mathrm{~m}$ & $208(6.4 \%)$ \\
West & $241(7.4 \%)$ & Force 4 - Moderate breeze $(20-28 \mathrm{~km} / \mathrm{h})$ & $346(10.7 \%)$ & $4-5 \mathrm{~m}$ & $96(3 \%)$ \\
East & $185(5.7 \%)$ & Force 5 - Fresh breeze $(29-38 \mathrm{~km} / \mathrm{h})$ & $257(7.9 \%)$ & $5-6 \mathrm{~m}$ & $32(1 \%)$ \\
South & $179(5.5 \%)$ & Force 6 - Strong breeze $(39-49 \mathrm{~km} / \mathrm{h})$ & $251(7.7 \%)$ & $6-7 \mathrm{~m}$ & $17(0.5 \%)$ \\
North & $113(3.5 \%)$ & Force 7 - Near gale $(50-61 \mathrm{~km} / \mathrm{h})$ & $99(3 \%)$ & $7-8 \mathrm{~m}$ & $7(0.2 \%)$ \\
Not indicated & $37(1.1 \%)$ & Force 8 - Gale $(62-74 \mathrm{~km} / \mathrm{h})$ & $44(1.4 \%)$ & $8-9 \mathrm{~m}$ & $2(0.1 \%)$ \\
& & Force 9 - Severe gale $(75-88 \mathrm{~km} / \mathrm{h})$ & $6(0.2 \%)$ & $9-10 \mathrm{~m}$ & $1(0.03 \%)$
\end{tabular}

operations peaked during $2013(\mathrm{n}=709$, mean per month = 59.1) (Fig. 1) and a marked seasonal variation were revealed with peak periods in summer months (December and January) (Fig. 2). The busiest month was December 2012 when 117 operations were performed.

Most operations occurred in the south-western coastal regions ( $n=1467,45.2 \%$ ) (Fig. 3 ).

Water-based assistance was the most frequent type of operation performed ( $n=2194,67.6 \%$ ), followed by landbased search and rescue $(n=341,10.5 \%)$ and air-based search and rescue $(n=42,1.3 \%)$. The NSRI further assisted during floods, firefighting, motor-vehicle accidents, whale disentanglement, crew replacement of vessels at sea, and body recovery searches (support services $n=669,20.6 \%$ ).

Water-based operations mostly related to medical evacuations of people aboard vessels at sea ( $n=269,12.3 \%)$, assisting small vessels ( 9 m or less) in need ( $n=264,12 \%)$ and drownings ( $n=230,10.5 \%$ ).

Sporting activities lead to 493 rescues; predominantly paddle-sport activities (185/493, 37.5\%), swimmers/divers (138/493, 28\%), and surfers/kite-surfers/windsurfers (122/493, 24.7\%). In total, 1021 boats were assisted (553 
Table 2. Rescued persons assisted by the National Sea Rescue Institute of South Africa according to age group

\begin{tabular}{ll}
\hline Age [years] & Number (\%) \\
\hline $0-12$ & $115(4.8 \%)$ \\
$13-19$ & $232(9.8 \%)$ \\
$20-29$ & $509(21.5 \%)$ \\
$30-39$ & $487(20.5 \%)$ \\
$40-49$ & $470(19.8 \%)$ \\
$50-59$ & $348(14.7 \%)$ \\
$>60$ & $211(8.9 \%)$
\end{tabular}

Table 3. Cause of death of individuals assisted by the National Sea Rescue Institute of South Africa during the 5-year study period

\begin{tabular}{ll}
\hline Cause of death & Number (\%) \\
\hline Fatal drowning & $138(75 \%)$ \\
Medical related death: & $17(9.2 \%)$ \\
Cardiovascular & $16(8.7 \%)$ \\
Asthma & $1(0.5 \%)$ \\
Trauma related death: & $16(8.7 \%)$ \\
Falls & $10(5.4 \%)$ \\
Head injuries & $2(1.1 \%)$ \\
Shark attack & $2(1.1 \%)$ \\
Motor-vehicle/motorcycle accident & $1(0.5 \%)$ \\
Gunshot wound & $1(0.5 \%)$ \\
Unknown & $13(7.1 \%)$ \\
Total & $184(100 \%)$
\end{tabular}

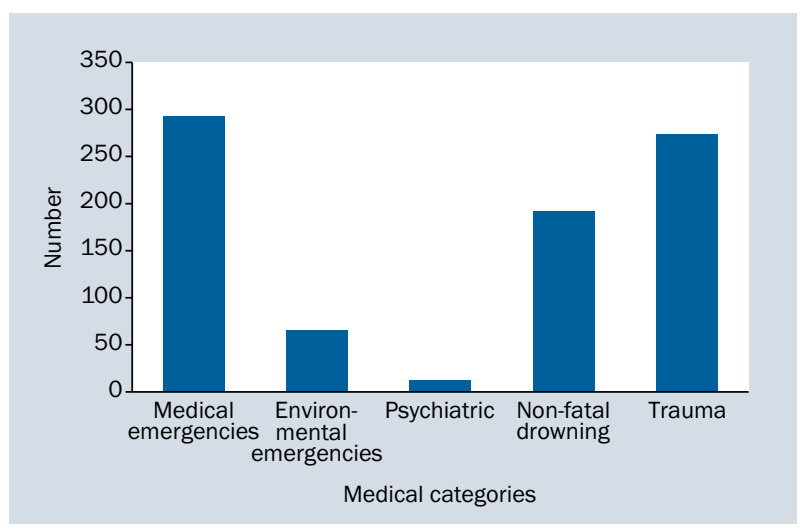

Figure 4. Distribution of individuals requiring medical assistance by the National Sea Rescue Institute of South Africa during the 5-year study period

towed); mostly sports and recreational crafts (737/1021, $72.2 \%)$ and commercial fishing crafts (277/1021, $27.1 \%)$.
The mean distance travelled offshore was $4.8 \mathrm{~km}$ (standard deviation [SD] 13.7, maximum $180 \mathrm{~km}$ ) and mean distance travelled from base $11.5 \mathrm{~km}$ (SD 23.8, maximum $370 \mathrm{~km}$ ).

Land-based search and rescue response $(n=341$, $10.5 \%$ ) included 50 (14.7\%) marooned persons or mountain hikers, of which 16 required medical evacuation.

The prevailing weather conditions at the time of the operation were recorded in 3209 (98.9\%) operations. South Easterly winds (1031/3209, 32.1\%) with swells of 1-2 m (1296/3209, 40.4\%) predominated (Table 1).

The NSRI assisted 3399 individuals (mean per operation $=2$, maximum per operation $=39$ ). Males accounted for $77 \%$ (2491/2372) of those requiring assistance. The mean age of rescued persons was 42 years (SD 24.6) with adults between 20 and 29 years of age (509/2896, 21.5\%) the biggest proportion (Table 2).

In total, 836 (25\%) individuals had non-fatal injuries or illnesses requiring medical assistance. Medical emergencies (293/836, 35\%), traumatic injuries (274/836, 32.8\%), and non-fatal drownings (192/836, 23\%) were the most frequent types of injury and illness (Fig. 4).

There were 184 (18\%) deaths recorded; drowning the most frequent cause $(138 / 184,75 \%)$ (Table 3$)$. Ten of the cardiovascular-related deaths were suspected to be from myocardial infarction. Two suicides occurred where the persons jumped to their death.

\section{DISCUSSION}

The purpose of this study was to describe the epidemiology of rescue operations performed by the NSRI of South Africa over a 5-year period.

The NSRI performed a mean of 649 operations per year from 2010 to 2015, with 709 operations the most in a calendar year (2013). This seems very little compared to the Royal National Lifeboat Institution, serving the coasts of the United Kingdom and the Republic of Ireland, which consistently launched more than 8000 lifeboats per annum $[12,13]$. Similarly, other European marine search and rescue institutions performed more than 2000 operations per year, including Germany's DGzRS, Deutsche Gesellschaft zur Rettung Schiffbrüchiger (2019 missions in the North and Baltic Seas during 2016), France's Les Sauveteurs En Mer (3552 missions around the French Coast in 2015), and Norway's Redningsselskapet (assisting 6447 boats in the coastal waters of Norway during 2016 [14-16]. However, one should be cautious to directly compare marine search and rescue institutions as they differ in too many aspects e.g. amount of ship traffic, persistent weather conditions, fleet size, etc.

Distinct seasonal variation in the number of search and rescue operations was observed, with peak periods in December and January. This finding is not surprising 
as it coincides with the summer holiday season in South Africa and is consistent with data from North American and Canadian National Parks where the largest proportion of operations were launched during the Northern Hemisphere summer (May to July) [5, 17, 18]. During the warm holiday season, holiday-goers are participating in water-based recreational and sporting activities (swimming, diving, surfing, kayaking, kite-surfing). Kitesurfing is favoured by extreme water-sports enthusiasts and South Africa (especially Cape Town) is becoming a very popular kitesurfing destination. This inevitably leads to an increase in sea rescues relating to kitesurfing [19].

Fortunately, most people assisted by the NSRI were not ill or injured $(n=2379,70 \%)$. A negligible difference was found between medical emergencies and trauma in the 836 injured individuals rescued (35\% vs. $32.8 \%$ ). Our data emphasize the need for search and rescue personnel to be able to manage a diverse range of medical problems, and to be sufficiently skilled in managing trauma and drowning cases.

Drowning remains a serious public health concern, claiming approximately 324,000 lives globally in 2015 alone. The WHO estimates drowning rates to be more than three times higher in low- and middle-income countries compared to high-income countries [1, 20]. South Africa had 3.19 deaths per 100,000 people due to drowning in 2015 , which is considerably higher compared to the United Kingdom $(0.6 / 100,000)$ and Germany $(0.69 / 100,000)$ [21]. Despite the higher incidence of drowning in South Africa, there remains a paucity in drowning-related data and further studies, specifically focusing on drowning, are recommended.

\section{LOCAL PERSPECTIVE}

The challenge for the NSRI is that it is a volunteer organisation staffed by personnel with limited emergency medical training beyond basic emergency care. Access to more advanced training by existing volunteers is limited by the training regime approved by the Health Professions Council of South Africa. The only solution available to the NSRI is to recruit trained professional emergency care providers to its ranks or to solicit support at the time of an incident. Ad hoc crew deployments without adequate sea going experience carry reasonable risk to both rescuer and patient.

The rescue of patients from ships at sea, by boat, provides unique challenges. For example, climbing $20 \mathrm{~m}$ up a pilot ladder, 'rescuing' the patient from inside the ship and then lowering them down between two objects moving in three dimensions requires experience and skill not taught in land-based institutions. Specialist training facilities are required. Helicopter rescue would be a solution but sufficient capacity and competence does not exist along the entire coastline.
Lastly, rescue tools and equipment need to be adapted for the maritime environment and the NSRI is constantly innovating to ensure patient and crew safety. Vacuum mattresses provide thermal, physical and float protection at sea and could be more widely used. The NSRI uses waterproof dry bags to package 'jump' bags and electronic equipment but water contamination is common and the cost of replacement high.

\section{LIMITATIONS OF THE STUDY}

The study was limited to South Africa and may not be representative of other African countries. As the NSRI mainly focuses on coastal and navigable water environments, there is a predilection towards incidents occurring on water. Nonetheless, as the first report of such nature, we believe it aids the existing knowledge gap.

Medical information was recorded by multiple sources with various levels of medical training. This resulted in an inherent level of inconsistency in reporting as only symptoms and not the final diagnosis was often documented.

As this study is a retrospective analysis of a pre-existing database, there is no external method available to confirm that the Station Commander appropriately declared a rescue operation or if NSRI rescue personnel accurately recorded data at the time of the operation or whether data was entered correctly onto the NSRI MIS database. Transcription errors may have occurred when data was captured onto MIS. However, all NSRI personnel are trained on the completion of the rescue mission reports and are routinely subjected to an internal quality assessment. The rescue base Station Commander crosschecks and validates the completed operation form prior to submitting it for entry onto the MIS database. Both these factors should ensure the quality of the data, while minimising missing data points. Incomplete data forms with missing variables may also limit the reliability and the generalizability of the study's results.

\section{CONCLUSIONS}

There is a paucity of literature describing marine rescues in South Africa. This descriptive study comprising rescue operations over a 5-year period, provides the first documented account of work carried out by the NSRI of South Africa. The findings of this study will better inform further research studies within the field of sea rescue and can thus be used to develop search and rescue strategies as well as training. The results may also suggest further preventative measures and public health strategies be implemented to minimise traumatic and medical incident severity and subsequent casualties at sea.

\section{REFERENCES}

1. WHO Global Report on Drowning: Preventing a leading killer [Internet]. 2014.http://www.who.int/violence_injury_prevention/ 
publications/drowning_global_report/Final_report_full_web. pdf?ua=1 (cited 2015 Jan 27).

2. Mortality and causes of death in South Africa, 2015: Findings from death notification. 2017.http://www.statssa.gov.za/publications/ P03093/P030932015.pdf (cited 2017 Sep 15).

3. Matthew J, Robertson C, Hofmeyr R. Update on drowning. South African Med J.2017; 107(7):562-565, doi:10.7196/samj.2017.v107i7.12609.

4. eaversuch F, Nimmo L, McCausland K JJ. A Review of Drowning Prevention Interventions for Children and Young People in High, Low and Middle Income Countries. J Community Health [Internet]. https://link-springer-com.ez.sun.ac.za/content/ pdf/10.1007\%2Fs10900-015-0105-2.pdf DOI 10.1007/s10900015-0105-2 (2017 Aug 23).

5. Heggie TW. Search and rescue in Alaska's national parks. Travel Med Infect Dis. 2008; 6(6): 355-361, doi: 10.1016/j.tmaid.2008.07.002, indexed in Pubmed: 18984480.

6. Adams AL, Schmidt TA, Newgard CD, et al. Search is a time-critical event: when search and rescue missions may become futile. Wilderness Environ Med. 2007; 18(2): 95-101, doi: 10.1580/06-WEME -OR-035R1.1, indexed in Pubmed: 17590071.

7. Canadian National Search and Rescue Manual [Internet]. http:// www.casara.ca/wp-content/uploads/2012/10/NSM_2000. pdf (cited 2015 Jan 13).

8. About Us | nsri.org.za [Internet]. http://www.nsri.org.za/about/ (cited 2015 Jan 12).

9. Ministry of Justice and Police. The Norwegian Search and Rescue Service [Internet]. www.redningsnett.no/Redningstjenesten/Informasjonshefter/The-Norwegian-Search-and-Rescue-Service (2002).

10. Marven C, Canessa R, Keller P. Exploratory Spatial Data Analysis to Support Maritime Search and Rescue Planning. In: Li J, Zlatanova S, Fabbri A. ed. Geomatics Solutions for Disaster Management SE - 18. Springer, Berlin Heidelberg 2007: 271-288.

11. National Search and Rescue Manual Volume I: National Search and Rescue System [Internet]. http://www.public.navy.mil/surfor/ Documents/3-50-1_Vol1.pdf (cited 2015 Jan 29).
12. Royal National Lifeboat Institution (GB). Royal National Lifeboat Institution (GB) [Internet]. 2016. https://rnli.org/ (cited 2017 May 1).

13. Riley D. Storms and statistics - another lifesaving year for the RNLI - News on Sailing Networks [Internet]. RNLI. 2016.http://www.sailingnetworks.com/news/read/35816 (cited 2017 Aug 31).

14. German Maritime Search, and Rescue Association. The Deutsche Gesellschaft zur Rettung Schiffbrüchiger (DGzRS) [Internet]. 2016. https://www.seenotretter.de/en/who-we-are/portrait/ (cited 2017 May 1).

15. The SNSM association. Les Sauveteurs En Mer [Internet]. 2015. https://www.snsm.org/page/bilans (cited 2017 May 7).

16. Redningsselskapet. Redningsselskapet. The Norwegian Society for Sea Rescue [Internet]. 2016. https://www.redningsselskapet.no/ english/ (cited 2017 May 16).

17. Ela G. Epidemiology of wilderness search and rescue in New Hampshire, 1999-2001. Wilderness Environ Med. 2004; 15(1): 11-17, doi: 10.1580/1080-6032(2004)015[0011:eowsar]2.0. co;2, indexed in Pubmed: 15040501.

18. Wild FJ. Epidemiology of mountain search and rescue operations in Banff, Yoho, and Kootenay National Parks, 2003-06. Wilderness Environ Med. 2008; 19(4): 245-251, doi: 10.1580/07-WEME -OR-141.1, indexed in Pubmed: 19099329.

19. Exadaktylos AK, Sclabas GM, Blake I, et al. The kick with the kite: an analysis of kite surfing related off shore rescue missions in Cape Town, South Africa. Br J Sports Med. 2005; 39(5): e26; discussion e26, doi: 10.1136/bjsm.2004.014795, indexed in Pubmed: 15849279.

20. WHO | Drowning Fact sheet. WHO [Internet]. 2016. http://www. who.int.ez.sun.ac.za/mediacentre/factsheets/fs347/en/ (cited 2017 Jan 28).

21. Seattle, WA: IHME U of W. Institute for Health Metrics and Evaluation (IHME). GBDCompareDataVisualization. [Internet] 2016.https://vizhub.healthdata.org/gbd-compare (cited 2017 May 16). 